\title{
Discriminatory Consequences of Non-discriminatory Standards
}

\author{
Aaditya Mattoo* \\ World Bank
}

\begin{abstract}
This paper shows that environmental, labour and other standards can be effective strategic policy instruments even when they are strictly non-discriminatory. This is because standards can be set which the foreign producer optimally chooses not to meet, allowing the domestic producer to monopolize the standardized segment of the market. Thus, it is important for policy to consider how much scope there should be for the imposition of unilaterally determined standards - which could impact negatively on trading partners even when they are non-discriminatory-rather than internationally negotiated standards.
\end{abstract}

- JEL Classifications: F12, L13.

- Key Words: Standards, Oligopoly, Strategic Trade Policy, Environment

\section{Introduction}

There is mounting pressure in the multilateral trading system to reconcile the apparently conflicting requirements of an open trading system and pursuit of policy objectives through environmental and labour standards-two so called "new issues". 1 The concern that these standards may create import barriers has usually arisen when it is more difficult for foreign producers to meet the standards, either because they do not have access to the relevant technology or because meeting the standards implies

\footnotetext{
*Corresponding Address: Aaditya Mattoo, the World Bank, 1818 H Street NW, Washington DC 20433, USA. Tel: +1-202-458-7611, Fax: +1-202-522-1159, Email: amattoo@worldbank.org

${ }^{1}$ See, for instance, Bhagwati (1996) and Bhagwati and Srinivasan (1996). This paper is concerned primarily with standards which are motivated by public welfare goals, such as protection of health, safety, and the environment. It does not deal with the many other types of standards, concerned inter alia with production efficiency, compatibility, technology diffusion and commercial communication (see National Research Council, 1995).

(O2000-Center for International Economics, Sejong Institution, all Rights Reserved.
} 
a greater increase in their costs. ${ }^{2}$ Accordingly, international trade law has attempted to discourage the use of standards that discriminate either among foreign producers or between domestic and foreign producers. This paper shows that even standards which are not discriminatory per se, can have discriminatory consequences in a market characterized by strategic interaction between firms.

The currently applicable international disciplines on standards are contained in the Agreement on Technical Barriers to Trade (TBT) concluded during the Uruguay Round of Multilateral Trade Negotiations (GATT, 1994). ${ }^{3}$ In addition to prohibiting the discriminatory use of standards, the TBT has two notable features. First, it creates a presumption in favour of harmonized international standards, ${ }^{4}$ without, however, denying any country the right to establish levels of standards it considers appropriate to fulfil legitimate objectives. ${ }^{5}$ Secondly, the TBT recognizes that mandatory standards that a country imposes may specify, not only product characteristics, but also their "related processes and production methods"-i.e. any aspects of the process which affects product characteristics, e.g. the use of organic rather than chemical fertilisers. The scope of certain voluntary standards, in particular, labelling requirements, is arguably wider, in that they could also pertain to processes or production methods unrelated to product characteristics. ${ }^{6}$ Environmental and labour lobbies have argued that the range of mandatory standards permissible under the TBT should be widened to include process standards which have no bearing on product characteristics. This would enable a country to restrict imports of products produced by methods which were detrimental to the environment or violated certain labour standards. ${ }^{7}$

The TBT provides no precise criteria to establish when a standard is

\footnotetext{
${ }^{2}$ See Robertson (1992).

${ }^{3}$ This Agreement revised the TBT Agreement reached during the Tokyo Round (GATT, 1979).

${ }^{4}$ The two predominant international standards-setting bodies in the world are the International Organization for Standardization (ISO) and the International Electrotechnical Commission (IEC), which are private organizations that develop standards in nearly all sectors of industry and technology. The ISO and IEC accept as members the national standards organizations, whether public or private, of their member countries. Standards are developed through consensus.

${ }^{5}$ These objectives include national security requirements, prevention of deceptive practices, protection of human health or safety, animal or plant life or health, or the environment.

${ }^{6}$ Voluntary standards are subject to disciplines similar to those imposed on mandatory standards, specified in a "Code of Good Practice." Furthermore, the TBT creates disciplines, not only for member governments, but also obliges them to take reasonable measures to ensure compliance by nongovernmental standard-setting bodies.

${ }^{7}$ These arguments are based on the supposed need to counter either global externalities-defined widely to include, for instance, concern in one country about working conditions in another-or the adverse effects on competitiveness of firms in countries which adopt higher standards than their trading partners.
} 
discriminatory. It is obvious that even identical standards can discriminate if some producers have to incur greater costs to meet them than other producers. This is necessarily true when the basis for the initial difference in costs between producers are differences in, say, the environment-related aspects of their products or production methods. Since the purpose here is to illustrate the discriminatory potential of legally permissible standards, we choose a definition which is considerably more stringent than any used under existing international trade law: a non-discriminatory standard is defined as one that entails an identical incremental cost to all producers. ${ }^{8}$ Even though such a standard is a hypothetical construct, it may have some empirical relevance. There are many situations in which the initial differences in costs between producers arise, not because of the different standards of their products or production methods, but due to factors such as differences in efficiency or access to cheaper inputs. An example would be a situation in which all producers of a particular product initially use diesel as a fuel and are required by the standard to change to petrol, but this does not affect the absolute difference in their costs due to differences in efficiency or access to cheaper complementary inputs.

It will be shown, using a simple duopoly model, that even when standards are subject to strict requirements of non-discrimination, their imposition may alter the market outcome in favour of the domestic producers. This is because when firms differ in costs, standards can be set which the foreign producer optimally chooses not to meet, allowing the domestic producer to monopolize the standardized segment of the market. Governments (or other standard-setting bodies) can therefore ensure, through ostensibly impartial actions, that the market equilibrium results in an outcome preferred by domestic producers. This provides some justification for the concern that, faced with the increased disciplines in international trade law on the use of either protection or state aid to assist domestic firms, governments may resort to standards, particularly those pertaining to production processes, as a form of strategic trade policy. It is thus important for policy to consider how much scope there should be for the imposition of unilaterally determined standards-which could have a negative impact on trading partners even when they are non-discriminatory-rather than internationally negotiated standards.

\footnotetext{
${ }^{8}$ Alternatively, the requirement could be that the standard entails the same proportionate increase in the costs of all producers. However, such a construct would present greater analytical difficulties without yielding more insights or having greater empirical relevance.
} 
The study of international trade policy for oligopolistic industries has shown that governments may shift market equilibria in favour of domestic firms by precommitting themselves to discriminatory policies, such as tariffs, subsidies, or even export taxes (see, for instance, Brander and Spencer(1984), Dixit(1984), Eaton and Grossman(1986). In a similar context, it has been shown that the environmental regulations imposed by governments on domestic firms may be influenced by strategic trade considerations (see Ulph, 1992, Ulph, 1994 and Barret, 1994). ${ }^{9}$ It has also been established that oligopolistic firms may benefit from standards-such as minimum wage norms that hurt rivals more than themselves (see Salop and Sheffman, 1983, Krattenmaker and Salop, 1986).

The contribution of this paper is to show that even when a particular standard implies identical incremental costs for all firms (domestic or foreign) who choose to meet it, certain firms may be favoured at the expense of others. Hence, the incentive to introduce such standards exists independently of other policy objectives though the existence of other objectives may strengthen the domestic political economy case, and provide international legitimacy, for the introduction of standards. Strategic considerations may, therefore, not only modify the form of, say, environmental policy (as in the papers mentioned above), but provide a reason for the pursuit of such policy. ${ }^{10}$

The next section describes certain economic aspects of standards which form the basis for the formal model. Section III first shows that even strictly nondiscriminatory standards can alter the market outcome in favour of the relatively high-cost firm. Next it is demonstrated that a country with a low cost firm would never have an incentive to introduce standards that the high cost firm cannot meet. It is also shown that if firms decide on whether to meet the standard sequentially,

\footnotetext{
${ }^{9}$ The focus of these papers is on producing countries whose response to negative environmental externalities associated with domestic production is affected by strategic trade concerns. Thus Ulph (1992) examines how governments choose between taxes or standards to achieve certain target levels of pollution when they are concerned about the impact on the strategic trading position of their industries. Barret (1994) and Ulph (1994) explore how the level of environmental taxes imposed on domestic firms is likely to differ when the overall objective function includes, not only pollution targets, but also strategic trade considerations.

${ }^{10} \mathrm{An}$ aspect of these results is similar to those obtained in models in which firms try to relax competition through product quality differentiation (Shaked and Sutton (1982)). However, here the environmental standard is treated as an exogenous policy variable, and the central issue is the relationship between firms' incentives to meet the standard and ex ante differences in their costs of production. It is thus implicitly assumed that consumers respond to standards introduced by the government, or other standard setting bodies, rather than to those introduced by the firms themselves. But the model does not inherently exclude the possibility that the standards are introduced by firms themselves.
} 
rather than simultaneously, then all firms may never meet a standard, even if it is set very low. The section concludes with a numerical illustration of these results. Section IV examines the implications of alternative assumptions, and Section V concludes the paper.

\section{The Basic Model}

Three aspects of standards need to be briefly considered before the formal model is constructed.

\section{A. Voluntary and Mandatory Standards}

The incentive to meet a voluntary standard, as for instance in certain ecolabelling programmes, arises from the existence of a section of consumers who are "concerned", even though there are others who are not. ${ }^{11}$ Thus, some consumers may refuse to buy aerosol-based products, tropical timber from forests which are not sustainably managed, or carpets made by child labour, while others pay little attention to these aspects of the product. Mandatory standards imposed by a government, however, force all consumers in a particular country to behave like concerned consumers, while consumers in other countries remain free to buy products which do not meet the standard. ${ }^{12}$ For instance, in 1990, while the United States imposed an embargo on imports of tuna caught by dolphin-unfriendly methods, most other countries did not impose any restriction on the import or sale of such tuna. Hence, a central aspect of both voluntary and mandatory standards is that they can lead to a segmentation of the market.

\footnotetext{
${ }^{11}$ For instance a study by the Roper Organization Inc. (1990) suggested that a quarter of the United States' adult population were environmentalists, slightly more than half were not, and the attitudes of the remaining quarter were not well defined. Jha (1993) quotes survey evidence which suggests that slightly over half of the consumers in North America purchased a product that they felt was better for the environment, boycotted a specific product which they felt was bad for the environment, or boycotted products made by a company which they felt was damaging the environment. See also OECD (1991).

${ }^{12}$ While voluntary standards can be introduced by the government, non-governmental organizations, or the firms themselves, only the government can introduce and enforce mandatory standards. In 1991, it was estimated that in the United States, there were around 52,000 government standards, and about 41,500 private standards set by technical and professional societies, industry associations, and other organizations, pertaining to virtually all branches of industry (National Research Council, 1995). It is difficult to identify the precise number of mandatory and voluntary standards since the boundary between mandatory and voluntary standards is not always distinct, especially since government standard writers frequently refer to privately developed, voluntary standards within the text of regulations and procurement specifications.
} 


\section{B. Impact of Standards on Costs}

The requirement to meet a certain standard may involve a change in variable costs, fixed costs, or both. For instance, the sustainable management of a forest may require replanting a tree for every tree cut, "low impact logging" which leads to lower harvesting yield, or other measures, all of which imply an increase in the variable cost (Simula and Oy, 1995). The installation of less polluting machinery is an example of change in fixed costs. In some cases, there may even be a choice between the two: if the object were to limit sulphur dioxide emissions, the switch in methods could involve a change in the type of fuels (e.g. substitution of oil or low-sulphur coal for high-sulphur coal), in which case variable costs are affected, or a change in the fixed inputs like machinery (e.g. installation of fluegas desulphurization equipment), in which case fixed costs are affected (Newbery, 1993). ${ }^{13}$

\section{Separability of Standards}

A firm may be able to meet a standard for only part of its output, or, for economic or legal reasons, may need to do so for its entire output. It would seem that the former is more likely to be the case for product standards while the latter is more frequently true for process standards. Thus, a firm may install a catalytic converter or airbag in cars it sells to the United States but not in cars it sells to Eastern Europe. But such separability is often not feasible either for economic or legal reasons. When technology is subject to economies of scale, it may simply not be profitable for the firms to supply the different segments of the market from different plants. ${ }^{14}$ Alternatively, the standard may have to be met by the firm rather than its product, on the basis of the conditions of production for its entire output. Such standards could pertain to the firms' aggregate emission of harmful gases, the manner in which it carries out product tests, its treatment of exhaustible

\footnotetext{
${ }^{13}$ Recently, Porter and van der Linde (1995) have pointed out that all standards need not be cost increasing. They suggest that properly designed environmental standards could trigger innovation that may partially or more than fully offset the costs of complying with them.

${ }^{14} \mathrm{~A}$ range of studies on environmental policy recently undertaken by the UNCTAD Secretariat have concluded that the economic use of certain environmentally-sound technologies is subject to significant economies of scale (UNCTAD, 1995). The evidence relates to industries such as leather and footwear, textiles and clothing (which require switching away from the use of certain chemicals and dyestuffs) and electronics (where bans apply to chemicals and solvents used in cleaning circuits and to the use of certain metals in these products, such as lead, cadmium and zinc). While the use of variable inputs is, in principle, separable between products, economies of scale arise because the plants themselves have to be modified for the use of different inputs.
} 
resources, or its labour standards. Furthermore, a variety of studies reveal that importing countries can and do monitor standards abroad (OECD, 1991). This is accomplished either through frequent on-site inspections or through reliance on national standardising bodies who have an incentive to maintain their reputations. $^{15}$

\section{The Formal Model}

This paper focuses for the most part on the analytically most demanding case of standards which are voluntary, involve a change in variable costs, and the firm needs to meet, for economic or legal reasons, for its entire output. Then, in Section $\mathrm{V}$, there is a brief discussion of each of the alternative possibilities discussed above, i.e. standards are mandatory, involve a change in fixed costs, and the firm can profitably produce both products which meet the standard and those which do not.

Demand Conditions: In the simplest scenario, the world market consists of $\mathrm{n}$ consumers with identical demand schedules. The inverse demand function is assumed to be linear and of the form, $p=a-b q .{ }^{16}$ When voluntary standards are introduced, $\mathrm{m}$ consumers switch to buying the product that meets the standard. ${ }^{17}$ If no firm meets the voluntary standard, all consumers continue to buy the substandard product.

Supply Conditions: The market structure is duopolistic and the market is supplied by a domestic and a foreign firm. The firms behave as Cournot duopolists, so that differences in marginal costs are reflected in differences in market shares. ${ }^{18}$ The fixed costs of the duopolists are sufficiently large to render unprofitable the entry of other firms and the setting up of multiple plants by the

\footnotetext{
${ }^{15}$ In the case of efforts to reduce dolphin mortality, the Inter-American Tuna Commission (IATC) has implemented a programme since 1986 which involves the placement of observers on all tuna vessels capable of fishing for tuna in association with dolphin.

${ }^{16}$ As Seade (1985), Bulow, et al. (1985) and others have shown, linearity does impose a significant restriction in oligopolistic situations. The assumption is necessary here to obtain explicit solutions for the profits of the firms in different situations. The implications of this assumption are discussed later.

${ }^{17}$ In the case of voluntary standards, it would be reasonable to assume greater consumer mobility between segments. The consumers could then balance their environmental or other concerns against price differences between segments. The assumption in the model, that concerned consumers behave rigidly, simplifies without significantly affecting the results.

${ }^{18}$ Results in oligopoly theory are sensitive to assumptions regarding both the number of competitors and the form of competition (price or quantity). The Cournot duopoly assumption enables a simple depiction of the strategic interaction between firms that differ in marginal costs. The implications of these assumptions are discussed later.
} 
existing firms. Marginal costs are assumed to be constant, and lower for one firm (foreign) than the other (domestic), $c^{f}<c^{d}$. For either firm, meeting the standard leads to an identical increase, e, in the marginal cost of production. A firm choosing to meet a certain standard must do so for its entire output.

Structure of the Game: The choices by the agents are depicted as a three stage game. In stage one, the standard setting body, referred to here as the domestic government, decides on the level of the standard, $e$. The foreign firm is assumed to be located in a country with insignificant domestic demand, so that there is no possibility of retaliatory standards. In stage two, firms independently choose from $\{S, N\}$, i.e. between meeting the standard, $S$, or not meeting it, $N$, taking into account the benefits and costs. Meeting a standard is beneficial for a firm because it provides access to a segment of the market, i.e. demand from the concerned consumers (or from the country with the mandatory standard). However, the increase in the marginal cost of production leads to reduced competitiveness in the standard-free segment of the market, which consists of the unconcerned consumers (or the rest of the world). The firms' decision on whether or not to meet the standard can be taken either simultaneously or sequentially. In the simultaneous move version of the game, this decision is irreversibly made by each firm in ignorance of the other firm's decision. In stage three, the firms choose output non-cooperatively, given the previous choices over $(e, S, N)$. As usual, the equilibrium is obtained by solving backwards, with the government's decision on where to set the standard determined by the anticipated response of firms, and the firms' decision on whether to meet the standard based on the profits anticipated at the market stage.

\section{E. Payoffs in the Market Stage}

The market stage of the game is relatively easy to solve. Firm i's profit in a segment of the market is given by ${ }^{19}$

$$
\Pi^{i}=k q^{i}\left(p-c^{i}\right)=k q^{i}\left[(a-b q)-c^{i}\right],
$$

where $k$ is the number of consumers in the segment, i.e. $k=n$ when the market is not segmented by standards, and if it is, then $k=m$ for the segment subject to standards, and $k=(n-m)$ for the segment not subject to standards; $q^{i}$ is the firm's output per consumer, so that $q=q^{i}$ if the firm is a monopolist in the segment of the

\footnotetext{
${ }^{19}$ In what follows, fixed costs, which are identical in all situations, are suppressed and their magnitude is assumed not to affect the outcome.
} 
market, and $q=q^{d}+q^{f}$ in duopoly; $c^{i}$ is the firm's constant marginal cost, i.e. $c^{i}=c^{d}$ or $\left(c^{d}+e\right)$ for firm $\mathrm{d}$ and $c^{f}$ or $\left(c^{f}+e\right)$ for firm $f$, depending on whether the standard has been met. Each firm chooses its output $q^{i}$ to maximize profits, and if it is a Cournot duopolist it takes as given the output of the other firm. The first order condition for a monopolist is

$$
\partial \Pi^{i} / \partial q^{i}=a-2 b q^{i}-c^{i}=0,
$$

and for a duopolist is

$$
\partial \Pi^{\mathrm{i}} / \partial q^{i}=a-2 b q^{i}-b q^{i}-c^{i}=0 .
$$

The second order conditions and market stability conditions are satisfied for the assumed linear demand function. For the duopolist, the first order condition for firm i (3) implicitly defines $q^{i}$ as a function of $q^{j}$. The equilibrium outputs can be found by solving these best-reply functions. It is straightforward to calculate the profits accruing to each firm in different situations.

If a standard is not introduced, or no firm meets the standard, the profits of the firms are given by ${ }^{20}$

$$
\begin{gathered}
\Pi^{d}(N, N)=n(1 / 9 b)\left(a-2 c^{d}+c^{\dagger}\right)^{2} \\
\Pi^{f}(N, N)=n(1 / 9 b)\left(a+c^{d}-2 c^{\dagger}\right)^{2}
\end{gathered}
$$

When a standard is introduced, each firm takes its output decision in the market stage given the previous choice of e by the government, and of either $S$ or $N$ by the firms. When only one firm meets the standard, it operates as a monopolist in the standardised segment and as a duopolist in the non-standardised segment, with its marginal costs at a level e higher than before (see (6) and (9) below); the firm that does not meet the standard continues to operate as a duopolist in the nonstandardised segment with unchanged costs (see (7) and (8) below). When both firms meet the standard, a duopoly is established in both segments of the market and marginal costs of both firms are at a level e higher than before (see (10) and (11) below). Since price in this linear model is independent of the number of consumers, and depends only on the market structure, the last situation can also be treated as an integrated market.

Outcome $(S, N)$ : the domestic firm meets the standard, the foreign firm does not

\footnotetext{
${ }^{20}$ In Section V, in the discussion of mandatory standards, a distinction is made between the situation in which a standard is not introduced and one in which no firm meets the standard.
} 


$$
\begin{gathered}
\Pi^{d}(S, N)=m(1 / 4 b)\left(a-c^{d}-e\right)^{2}+(n-m)(1 / 9 b)\left(a-2 c^{d}+c^{f}-2 e\right)^{2} \\
\Pi^{f}(S, N)=(n-m)(1 / 9 b)\left(a+c^{d}-2 c^{f}+e\right)
\end{gathered}
$$

Outcome $(N, S)$ : the domestic firm does not meet the standard, the foreign firm does

$$
\begin{gathered}
\Pi^{d}(N, S)=(n-m)(1 / 9 b)\left(a-2 c^{d}+c^{f}+e\right)^{2} \\
\Pi^{f}(N, S)=m(1 / 4 b)\left(a-c^{f}-e\right)^{2}+(n-m)(1 / 9 b)\left(a+c^{d}-2 c^{f}-2 e\right)^{2}
\end{gathered}
$$

Outcome $(S, S)$ : both firms meet the standard

$$
\begin{aligned}
& \Pi^{d}(S, S)=n(1 / 9 b)\left(a-2 c^{d}+c^{f}-e\right)^{2} \\
& \Pi^{f}(S, S)=n(1 / 9 b)\left(a+c^{d}+2 c^{f}-e\right)^{2}
\end{aligned}
$$

Note that the profits of each firm are continuous in $e$. If only one firm meets the standard, its profits clearly decline with e, while the profits of the firm which does not meet the standard increase with $e$. If both firms meet the standard, profits of each decline with $e$ but less rapidly than if only one had met the standard, because in the former situation there is no decline in relative competitiveness. ${ }^{21}$ It is thus evident that $\Pi^{d}(N, S), \Pi^{d}(S, S), \Pi^{f}(S, N)$ and $\Pi^{f}(S, S)$ are continuously declining in $e$ over the relevant range, $\Pi^{d}(S, N)$ and $\Pi^{f}(N, S)$ are continuously increasing in $e$ over the relevant range, while $\Pi^{d}(N, N)$ and $\Pi^{f}(N, N)$ do not change with $e$.

The prior stage game in which firms decide whether to meet the standard can be depicted in normal form as follows.

\begin{tabular}{clll} 
& & \multicolumn{2}{c}{ Foreign firm } \\
Domestic firm & $S$ & $\Pi^{d}(S, S), \Pi^{f}(S, S)$ & $\Pi^{d}(S, N), \Pi^{f}(S, N)$ \\
& $N$ & $\Pi^{d}(N, S), \Pi^{f}(N, S)$ & $\Pi^{d}(N, N), \Pi^{f}(N, N)$
\end{tabular}

\section{Standards and Market Structure Equilibria}

\section{A. Strategic Standards: Simultaneous Moves}

Consider a situation in which there are at least some concerned consumers, $\mathrm{m}$,

\footnotetext{
${ }^{21}$ It has been noted that in oligopolistic competition, generalized cost increases may have profitable consequences by serving to dampen competition between firms (see Seade, 1985). This possibility does not arise with linear demand.
} 
and firms must decide simultaneously on whether to meet a standard. It is possible to show that provided the standard is set at a sufficiently low level (e), given the magnitude of concern (m), there exists a dominant strategy Nash equilibrium in which both firms choose to meet it. Conversely, if the standard is set at a sufficiently high level, given the magnitude of concern (m), then there exists a dominant strategy Nash equilibrium in which both firms choose not to meet it. The interesting result is the following: provided that the size of the segment subject to standards is not too large, there exist a set of standards which lead to an equilibrium in pure strategies in which only the relatively high cost firm meets the standard. Furthermore, the profits of the high cost firm may be higher and the profits of the low cost firm lower in this equilibrium than they would have been if no firm had met the standard.

There are four possible equilibrium configurations, $(S, N),(N, S),(S, S)$ and $(N, N)$. Necessary and sufficient conditions for these configurations to be pure strategy Nash equilibria are the following:

$(N, N): \Pi^{d}(N, N) \geq \Pi^{d}(S, N)$ and $\Pi^{f}(N, N) \geq \Pi^{f}(N, S)$;

$(S, N): \Pi^{d}(S, N) \geq \Pi^{d}(N, N)$ and $\Pi^{f}(S, N) \geq \Pi^{f}(S, S)$;

$(N, S): \Pi^{d}(S, N) \geq \Pi^{d}(S, S)$ and $\Pi^{f}(N, S) \geq \Pi^{f}(N, N)$;

$(S, S): \Pi^{d}(S, S) \geq \Pi^{d}(N, S)$ and $\Pi^{f}(S, S) \geq \Pi^{f}(S, N)$.

The parameters underlying these equilibria are $\mathrm{m}$, which is exogenous, and e, which is chosen by the domestic government. There are four profitability comparisons involved in the above. It is convenient to define functions $e_{i}=e_{i}(m)$, for $i \in\{1,2,3,4\}$ by solving the above profitability comparisons at equality:

$e_{1}(m)$ solves $\Pi^{d}(S, N)=\Pi^{d}(N, N)$; so that if $e>e_{1}(\mathrm{~m})$ then $\Pi^{d}(S, N)<\Pi^{d}(N, N)$;

$e_{2}(m)$ solves $\Pi^{f}(N, S)=\Pi^{f}(N, N)$; so that if $e>e_{2}(\mathrm{~m})$ then $\Pi^{f}(N, S)<\Pi^{f}(N, N)$;

$e_{3}(m)$ solves $\Pi^{f}(S, S)=\Pi^{f}(S, N)$ so that if $e>e_{3}(\mathrm{~m})$, then $\Pi^{f}(S, S)<\Pi^{f}(S, N)$;

$e_{4}(m)$ solves $\Pi^{d}(S, S)=\Pi^{d}(N, S)$; so that if $e>e_{4}(\mathrm{~m})$, then $\Pi^{d}(S, S)<\Pi^{d}(N, S)$

Equilibrium outcomes in pure strategies occur as follows, for given $m$ :

$$
\begin{gathered}
e \geq \max \left[e_{1}(m), e_{2}(m)\right] \Rightarrow(N, N) \\
e \leq \min \left[e_{3}(m), e_{4}(m)\right] \Rightarrow(S, S) \\
e \in\left[e_{1}(m), e_{3}(m)\right] \Rightarrow(S, N) \\
e \in\left[e_{2}(m), e_{4}(m)\right] \Rightarrow(N, S)
\end{gathered}
$$

An example of the possibilities is presented in Figure 1, where parameter space 
is divided into seven regions. These include the four regions (A, B, D, G) where each of the above four possibilities is a unique pure strategy equilibrium, two additional regions $(\mathrm{C}, \mathrm{F})$ where multiple equilibria are possible, and one region (G) where no pure strategy equilibrium exists.

This Section will focus on demonstrating the existence of regions A, G and B. In particular, a choice of e from region $\mathrm{B}$ ensures an equilibrium $(S, N)$ in which only the high cost domestic firm adopts the standard, and makes greater profits than in a non-standard $(N, N)$ equilibrium. This validates the idea of the standard being chosen for a strategic purpose, to benefit the domestic firm. The other regions are discussed using a numerical example in the following Section.

Proposition 1: If the firms' simultaneously choose between $S$ and $N$, then (i) for $m>0$ and sufficiently small $e,(S, S)$ is a dominant strategy Nash equilibrium, i.e. both firms choose to meet the standard;

(ii) for $m>0$ and sufficiently large $e,(N, N)$ is the dominant strategy Nash equilibrium, i.e. neither firm chooses to meet the standard;

(iii) for relatively small $m \in\left[0, \mathrm{~m}^{*}\right]$ and a range of positive $e \in\left[e_{*}, e^{*}\right],(S, N)$ is the unique Nash equilibrium, i.e. the high cost firm chooses to meet the standard and the low cost firm does not.

Parts (i) and (ii) of Proposition 1 are transparent. That 1(i) holds is easy to prove by evaluating the profit functions in the vicinity of $e=0$ for any $m>0$ : for the domestic firm, $\Pi^{d}(N, S)<\Pi^{d}(S, S)$ and $\Pi^{d}(N, N)<\Pi^{d}(S, N)$, and for the foreign firm, $\Pi^{f}(S, N)<$ $\Pi^{f}(S, S)$ and $\Pi^{f}(N, N)<\Pi^{f}(N, S)$. Of course, for large $\mathrm{m}$, large e can also lead to an $(S, S)$ equilibrium (see Figure 1). Proposition 1(ii) is also obvious since, for any $m>0$, it is possible to conceive of an extremely high standard, i.e. a very large $e$, at which profits from meeting the standard are less than zero, so that: for the domestic firm, $\Pi^{d}(N, S)>\Pi^{d}(S, S)$ and $\Pi^{d}(N, N)>\Pi^{d}(S, N)$, and for the foreign firm, $\Pi^{f}(S, N)>$ $\Pi^{f}(S, S)$ and $\Pi^{f}(N, N)>\Pi^{f}(N, S)$.

The proof of Proposition 1(iii) consists in showing first, that in e,m space, $e_{1}(m)$ lies above $e_{2}(m)$, i.e. $e_{1}>e_{2}$ for any $m \in[0, n]$. This implies that, given that the other firm has not met the standard, there exist a set of standards $e \in\left[e_{2}, e_{1}\right]$ that the high cost firm finds it profitable to meet and the low cost firm does not. The second step is to show that, for relative small values of $\mathrm{m}, \mathrm{e}_{1}(\mathrm{~m})$ lies above $\mathrm{e}_{3}(\mathrm{~m})$, i.e. $e_{1}>e_{3}$ for $m \in\left[0, m^{*}\right]$. This implies that for relatively small $\mathrm{m}$, there exist a range of standards $e \in\left[e_{3}, e_{1}\right]$ which the low cost firm does not find it profitable to meet given that the 
high cost firm has met them. There thus exists for $m \in\left[0, m^{*}\right]$ an interval $e \in\left[\max \left[e_{2}, e_{3}\right], e_{1}\right]$, at which not meeting the standard is the dominant strategy for the low cost firm, and given this, meeting the standard is the preferred strategy for the high cost firm. As noted above, region B in Figure 1 depicts the combinations of e and $\mathrm{m}$ for which $(S, N)$ is the unique Nash equilibrium.

Lemma 1: Given that the other firm has not met the standard, the highest standard that the low cost firm can profitably meet is lower than the highest standard that the high cost firm can profitably meet, irrespective of the size of the standardized segment, i.e. $e_{1}>e_{2}$ for any $m \in[0, n]$.

We can write $\Pi^{d}(S, N)-\Pi^{d}(N, N)=0$, and $\Pi^{f}(N, S)-\Pi^{f}(N, N)=0$, using (4), (5), (6) and (9) as follows:

$$
\begin{gathered}
m\left[(1 / 4 b)\left(a-c^{d}-e\right)^{2}-(1 / 9 b)\left(a-2 c^{d}+c^{f}\right)^{2}\right]-(n-m)(1 / 9 b) \\
{\left[\left(a-2 c^{d}+c^{f}\right)^{2}-\left(a-2 c^{d}+c^{f}-2 e\right)^{2}\right]=0,} \\
m\left[(1 / 4 b)\left(a-c^{f}-e\right)^{2}-(1 / 9 b)\left(a+c^{d}-2 c^{f}\right)^{2}\right]-(n-m)(1 / 9 b) \\
{\left[\left(a+c^{d}-2 c^{f}\right)^{2}-\left(a+c^{d}-2 c^{f}-2 e\right)^{2}\right]=0 .}
\end{gathered}
$$

The first term on the left hand side of each equation represents the gain in moving from the existing duopoly situation to a monopoly position vis-a-vis $\mathrm{m}$ consumers, by accepting an increase $e$ in marginal cost. The second term represents the loss in duopoly profits vis-a-vis the remaining $(m-n)$ consumers caused by an increase e in marginal cost. It can be shown that an increase in costs hurts the high cost firm less than the low cost firm, and, less obviously, that the high cost firm obtains greater additional benefits from gaining exclusive access to the concerned segment of the market, i.e.

$$
\begin{gathered}
(n-m)(1 / 9 b)\left[\left(a-2 c^{d}+c^{f}\right)^{2}-\left(a-2 c^{d}+c^{f}-2 e\right)^{2}\right]<(n-m)(1 / 9 b) \\
{\left[\left(a+c^{d}-2 c^{f}\right)^{2}-\left(a+c^{d}-2 c^{f}-2 e\right)^{2}\right],} \\
m\left[(1 / 4 b)\left(a-c^{\mathrm{d}}-e\right)^{2}-(1 / 9 b)\left(a-2 c^{d}+c^{f}\right)^{2}\right]>m\left[(1 / 4 b)\left(a-c^{f}-e\right)^{2}-(1 / 9 b)\right. \\
\left.\left(a+c^{d}-2 c^{f}\right)^{2}\right] .
\end{gathered}
$$

Inequality (14) simplifies to $c^{f}-c^{d}<0$ and inequality (15) to $2 a-c^{d}-c^{f}+6 e>0$. To see the intuition for inequality (14), note that an increase in constant marginal costs leads to a larger decline in the profits of the low cost firm than of the high cost firm for the following reason. An increase in a firm's marginal costs has a direct effect on its profits, and an indirect effect through induced changes in the rival's output and hence market price. Given our assumptions, both effects have a 
negative sign, and their magnitude depends on the firm's initial output. Since the low cost firm initially produces a larger output than the high cost firm, any cost increase has a greater adverse impact on its profits.

Now it may seem that the low cost firm also obtains greater benefits from meeting a standard because it makes larger profits from a monopoly position in the standardised segment of the market. However, it is relatively less attractive for the low cost firm to move from a duopolistic to a monopolistic position in a segment of the market (15). For the low cost firm, the increase in profits from creating a monopoly position in the concerned segment derives from the exclusion of a relatively inefficient rival, while for a high cost firm, the increase in profits arises from excluding a relatively efficient rival. This is for the same reason that entry by a high cost firm hurts a low cost firm less than entry by a low cost firm hurts a high cost firm. Thus, the low cost firm incurs greater costs and obtains smaller benefits from meeting a standard than does a high cost firm.

Hence, $e_{1}>e_{2}$ for any $m \in[0, n]$. This implies that, given that the other firm has not met the standard, there exist a set of standards $e \in\left[e_{2}, e_{1}\right]$ that the high cost firm finds it profitable to meet and the low cost firm does not.

Lemma 2: Given that the high cost firm has met the standard, there exists, for relatively small $\mathrm{m}$, a range of standards $e \in\left[e_{3}, e_{1}\right]$ which the low cost firm does not find it profitable to meet, i.e. $e_{3}<e_{1}$ for $m \in\left[0, m^{*}\right]$. For relatively large $m$, given that the high cost firm has met a standard, the low cost firm will meet it also, i.e. $e_{3}>e_{1}$ for $m \in\left[m^{*}, n\right]$.

Note that when $m=0$,

$$
\left.\left.\Pi^{d}(S, N)=\Pi^{d}(N, N)\right] \Pi^{e}=0 \text { and } \Pi^{f}(S, S)=\Pi^{f}(S, N)\right] \Pi^{e}=0 .
$$

When $m=n$,

$$
\left.\left.\Pi^{d}(S, N)=\Pi^{d}(N, N)\right] \Rightarrow e=(1 / 3)\left(a+c^{d}-2 c^{f}\right) \text { and } \Pi^{f}(S, S)=\Pi^{f}(S, N)\right] \Rightarrow e=\left(a+c^{d}-2 c^{f}\right) .
$$

Thus, for high $\mathrm{m}$ (close to $\mathrm{n}$ ), the values of e which solve $\Pi^{d}(S, N)=\Pi^{d}(N, N)$ are smaller than those which solve $\Pi(S, S)=\Pi^{f d}(S, N)$, i.e. $e_{1}(m)$ lies below $e_{3}(m)$.

Note that $e_{1}(m)$ runs from $(0,0)$ to $\left((1 / 3)\left(a+c^{d}-2 c^{f}\right), n\right)$, while $e_{3}(m)$ runs from $(0,0)$ to $\left(\left(a+c^{d}-2 c^{f}\right), n\right)$.

Furthermore,

$$
\begin{aligned}
& d e_{1} /\left.d m\right|_{\Pi_{(S, N)=\Pi_{(N, N)}}=}\left[9\left(a-c^{d}-e\right)^{2}-4\left(a-2 c^{d}+c^{f}-2 e\right)^{2}\right] /\left[18 m\left(a-c^{d}-e\right)+\right. \\
&\left.16(n-m)\left(a=2 c^{d}+c^{f}-2 e\right)\right]>0,
\end{aligned}
$$




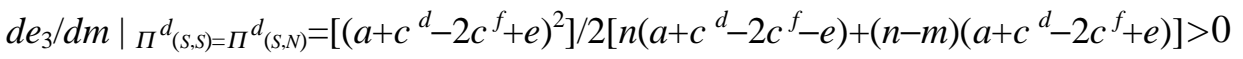

It is also evident that

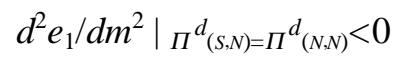

$$
\begin{aligned}
& \text { and } d^{2} e_{3} /\left.d m^{2}\right|_{\Pi_{(S, S)} f_{\Pi}} ^{f_{(S, N)}}>0 \text {, }
\end{aligned}
$$

i.e. $e_{1}(m)$ is strictly concave and $e_{3}(m)$ is strictly convex. Moreover, if we evaluate the first derivatives at $(0,0)$,

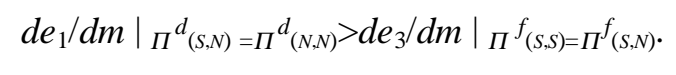

Inequalities (16) to (20) show that for low values of $m, e_{1}(m)$ lies above $e_{3}(m)$ as shown in Figure 1 implying that the values of e which solve $\Pi^{d}(S, N)=\Pi^{d}(N, N)$ are greater than those which solve $\Pi^{f}(S, S)=\Pi^{f}(S, N)$.

The intuition for this result lies in the greater sensitivity of e to changes in $\mathrm{m}$ when the other firm has already met the standard compared to when it has not. When the other firm has not met the standard, a firm compares the advantage of converting a duopoly situation into a partial monopoly with higher costs. When the other firm has met the standard, the comparison is between profits from a smaller market and a larger market with increased costs: when $\mathrm{m}$ is small there may not be much difference, but as $\mathrm{m}$ grows, the difference grows rapidly. An interesting implication of this result is that if the segment of concerned consumers (or, in the case of mandatory standards, a country) constitutes a very large share of the world market, then a strategic standard cannot be implemented to benefit a high cost domestic firm, because any such standard would always be met by the

Figure 1. Equilibrium outcomes with different levels of standards and consumer concern.

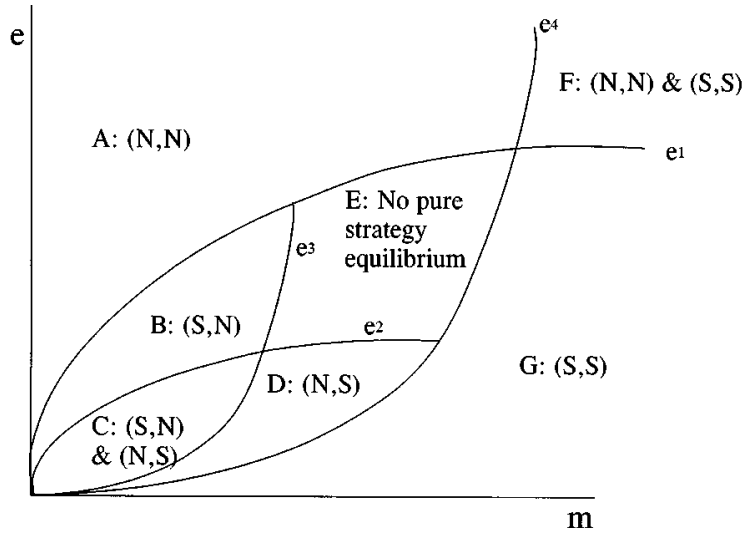


foreign firm. In the numerical example given below, it is possible to show that the threshold market size, $m^{*}>n / 2$. This suggests that, in certain situations, even if the concerned segment (or a particular country) accounts for more than half the share of the world market, a strategic standard could still be implemented.

Finally, it can also be shown that the high cost firm's decision to meet the standard may hurt or benefit the low cost firm, depending on the levels of e and $\mathrm{m}$. In a range of situations, the impact on profits of a loss of a segment of the market is not offset by the gain due to an increase in competitiveness (caused by an increase in the rival's costs), i.e. $\Pi^{f}(S, N)<\Pi^{f}(N, N){ }^{22}$ This is illustrated below using a numerical example.

In sum, the government of the country in which the high cost firm is located would have an incentive to introduce standards in the range for which Proposition 2(iii) holds. Given that the profits of its firm are declining in $e$, it would set the lowest possible standard which its firm would meet and the foreign firm would not. This result has been proved for the case of voluntary standards, but as will be evident in Section V, it also holds for mandatory standards. It is also possible to show that the government of the country with the low cost firm would have a strategic incentive to introduce standards to locate the equilibrium in region $\mathrm{D}$ in Figure 1 . For any given $\mathrm{m}$, strategic standards introduced by the low cost country are likely to involve smaller cost increases than the strategic standards introduced by the high cost country. This situation is also illustrated numerically below.

\section{B. Exclusionary Standards}

It is evident that there must exist some standards which are so high that only the low cost firm can meet them. This would be the case if $a-c^{d}<e<a-c^{f}$, i.e. the high cost firm would be excluded from meeting the standard. How do these "exclusionary standards" relate to the "strategic standards" discussed so far?

It emerges that the low cost firm cannot make higher profits by meeting an exclusionary standard than it does in the absence of standards, and, therefore, would not voluntarily meet it. In other words, an exclusionary standard cannot serve a strategic purpose. To see this, we find the maximum value of $e$ for which $\Pi^{f}(N, S)>\Pi^{f}(N, N)$, i.e. the highest standard that the low cost firm could meet and yet

\footnotetext{
${ }^{22}$ It is possible to show that the locus of combinations of e and $\mathrm{m}$ for which $\Pi^{f}(S, N)=\Pi^{f}(N, N)$, is convex and lies above $e_{3}(m)$, the locus of combinations of e and $\mathrm{m}$ for which $\Pi^{f}(S, S)=\Pi^{f}(S, N)$. The former locus thus passes through region B in Figure 1-points to the left of it represent situations in which the low cost firm also gains, and points to the right of it represent situations where it loses. This accords with the intuition that the low cost firm is less likely to lose if $\mathrm{m}$ is small.
} 
make higher profits than in the no standards situation.

$$
e_{\max }: m(1 / 4 b)\left(a-c^{f}-e\right)^{2}+(n-m)(1 / 9 b)\left(a+c^{d}-2 c^{f}-2 e\right)^{2}>n(1 / 9 b)\left(a+c^{d}-2 c^{f}\right)^{2} .(21)
$$

Clearly the maximum e will obtain when $m=n$, i.e. the whole market is subject to standards. What is the maximum e that the low cost firm would "pay" to become a monopolist in the whole market? The solution is $e=1 / 3\left(a-2 c^{d}+c^{f}\right)$. This is clearly less than $\left(a-c^{d}\right)$ the lowest standard that the high cost firm would not be able to meet.

Proposition 2: A low cost firm would not voluntarily meet a standard that the high cost firm cannot meet. That is, $\Pi^{f}(N, S)<\Pi^{f}(N, N)$ for all $e>a-c^{d}$.

An implication of this result is that a country with a low cost firm would never have a strategic incentive to introduce exclusionary standards. The intuition for this result is quite simple. The maximum profit margin that the low cost firm could charge as a monopolist after meeting the exclusionary standard would have to be less than $a-\left(c^{f}+a-c^{d}\right)=\left(c^{d}-c^{f}\right)$, since its cost would have increased by at least $a-c^{d}$. However, if the firm does not meet the standard, and charges a price slightly lower than $c^{d}$, it will obtain virtually the same margin over a larger output-since the absolute level of the price would be lower. Thus the low cost firm cannot do better by meeting an exclusionary standard than it does in the absence of standards.

\section{Strategic Standards: Sequential Moves}

We now assume that stage two of the game, i.e. when the firms' decide on whether to meet the standard, is played sequentially rather than simultaneously. Since the firms move, not at the same time, but one after the other, they have the possibility of observing and reacting to each others decisions. The decision to meet the standard is treated as irreversible while the decision not to meet the standard can be reversed. ${ }^{23}$ The firms move alternately and enter stage three, i.e. the market stage where the profit payoffs are obtained, either (i) when one firm has met the standard, and the other has had an opportunity to react, either by meeting the standard or not meeting it, or (ii) when each firm has had one opportunity to react to the decision by the other not to meet the standard. These assumptions make it possible to present the argument with the greatest simplicity (see Figure

\footnotetext{
${ }^{23}$ Alternatively, firms only precommit to a decision to meet the standard but not to the decision to not meet the standard. In the simultaneous move version, they precommit to either decision.
} 
Figure 2. Firms adopt standards sequentially.

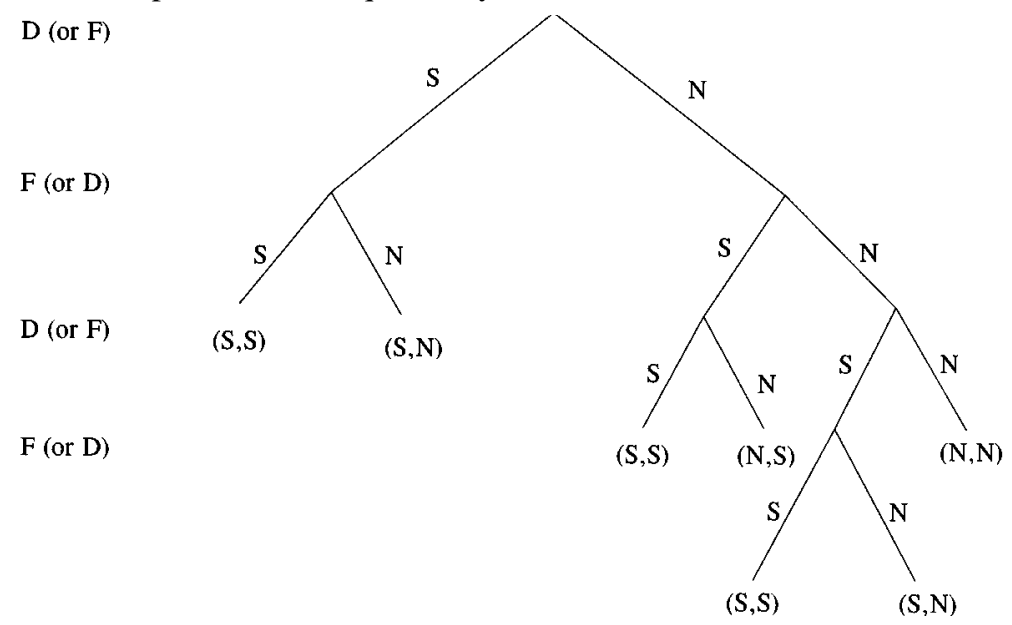

2). Certain interesting conclusions follow.

Proposition 3: If the firms' sequentially choose between $S$ and $N$, then

(i) for $m>0$ and sufficiently small $e$, the sub-game perfect equilibrium is $(N, N)$, i.e. neither firm chooses to meet the standard;

(ii) for $m>0$ and sufficiently large $e$, the sub-game perfect equilibrium is $(N, N)$, i.e. neither firm chooses to meet the standard;

(iii) for relatively small $\mathrm{m} \in\left[0, m^{*}\right]$ and for a range of positive $e \in\left[e_{*}, e^{*}\right]$, the subgame-perfect equilibrium is either $(S, N)$ or $(N, S)$ depending on which firm moves first.

Part (i) is possibly the most interesting and is easily proved. For sufficiently small e, the game has a Prisoners' Dilemma payoff structure. Beyond what has been shown in the context of Proposition (i), note that $\Pi^{d}(S, S)<\Pi^{d}(N, N)$ and $\Pi^{f}(S, S)<\Pi^{\mathrm{f}}(N, N)$, i.e. if both firms meet the standard, then the profits of each are lower than if neither had met the standard. If consumers are unwilling to pay more for environmental quality of the products, then meeting the standard is a pure cost for all firms.

In a sequential move game, a strategy of the form "do not meet the standard if the other firm does not, meet it if the other does" could sustain an $(N, N)$ equilibrium in which neither firm meets the standard. The threat to meet the standard in retaliation for the other firm doing so would be credible since $(S, S)$ is a Nash equilibrium of the game. Thus, ironically, if environmental standards are costly but so low that all firms seem to have an incentive to meet them, then no firm may actually meet them. 
In the case examined here, with sequential moves, a firm would meet a standard only if it were set at an intermediate level. The decision would be a strategic one, and would be taken only when the other firm has no incentive to retaliate. Within the set of equilibria consequent upon intermediate standards, there are those at which one firm makes higher profits than if no standard were introduced. But a firm with a first mover advantage would also meet a standard in certain situations even if it gets lower profits than in the no standards situation in order to deter the other firm from meeting the standard. No proof is provided here for parts (ii) and (iii) of Proposition 3, but they are illustrated in the next section.

\section{A numerical example}

The results can be illustrated using a numerical example. The following parameter values are assumed: $n=100, m=30, a=10, c^{\mathrm{d}}=2, c^{f}=1$. The value of $\mathrm{e}$ is allowed to vary between 0 and 2 . The games in normal form for selected values of e are presented below. The question is: would a government have an incentive to introduce a standard purely to increase the profits of its firm, and, if so, where would the standard be set?

$e=0.1$

$\begin{array}{lccc} & & & \text { Foreign firm } \\ & & S & N \\ \text { Domestic firm } & S & 529,1089 & 828,793 \\ & N & 392,1341 & 544,1111\end{array}$

As noted above, this game ( $e=0.1$, located in region $\mathrm{G}$ in Figure 1 ) has a Prisoners' Dilemma payoff structure, and $(S, S)$ is the dominant strategy Nash equilibrium if firms decide simultaneously on whether or not to meet the standard. Both firms could have done better if neither had met the standard. If the firm's decision on whether to meet the standard is taken sequentially rather than simultaneously, then the credible threat of meeting the standard in retaliation for the other firm doing so sustains a perfect equilibrium in which no firm meets the standard.

In the following game ( $e=0.63$, located in region $\mathrm{D}$ in Figure 1$)$, meeting the standard is the dominant strategy for the foreign firm. Given that the foreign firm will meet the standard, the preferred strategy for the domestic firm is not to meet the standard. $(N, S)$ is thus the unique Nash equilibrium of this game. Note that in this equilibrium, the payoff to the domestic firm (453) is lower than its payoff in 
the no standards situation (544), while the payoff to the foreign firm is higher (1119 rather than 1111).

$e=0.63$

Domestic firm
The next game (e=0.7, located in region E in Figure 1) has the payoff structure
of "Matching Pennies", and no equilibrium in pure strategies exists. If the
predicted outcome is that both firms make the same choice, the domestic firm has
an incentive to deviate, while the foreign firm would prefer to deviate from any
prediction in which choices do not match. It is, however, known that in all such
games an equilibrium in mixed strategies exists, in which each firm randomizes
between pure strategies (Fudenberg and Tirole, 1992).

$e=0.7$

Foreign firm

$\begin{array}{cc}S & N \\ 441,961 & 644,890\end{array}$

$\underline{\text { Domestic firm }}$

$N$

461,1092

544,1111

In the following game ( $e=1.0$, located in region B in Figure 1), not meeting the standard is the dominant strategy for the foreign firm. Given that the foreign firm will not meet the standard, the preferred strategy for the domestic firm is to meet the standard. $(S, N)$ is thus the unique Nash equilibrium of this game. In this equilibrium, the payoff to the foreign firm (941) is lower than its payoff in the no standards situation (1111), while the payoff to the domestic firm is higher (562 rather than 544).

$e=1.0$

Foreign firm

$S$

400, 900

N

562,941

Domestic firm 
The sequential move version of this game produces an identical result provided that the domestic firm moves first. However, if the foreign firm moves first, the perfect equilibrium of the game would be $(N, S)$ rather than $(S, N)$, i.e. the foreign firm would meet the standard and the domestic firm would not. This is because the foreign firm would ideally like no firm to meet the standard, but if a firm is going to meet the standard anyway, then it would rather be the one to do so; the domestic firm would have preferred to be the firm to meet the standard, but given that the foreign firm has already met the standard, it prefers to avoid head-on rivalry and chooses instead to specialize in the non-standardized segment. This is an example of the low cost firm meeting the standard, not because it is inherently profitable, but to deter entry by the high cost firm into the segment subject to standards.

In the final game $(e=1.7$, located in region $\mathrm{A}$ in Figure 1$)$, representing high values of $e,(N, N)$ is the dominant strategy Nash equilibrium and no firm will meet the standard.

$e=1.7$

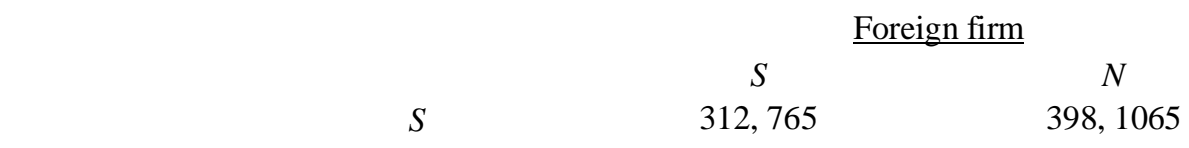

$\underline{\text { Domestic firm }}$

$N \quad 589,738 \quad 544,1111$

The domestic government would clearly have an incentive to set a standard in the vicinity of $e=1 .{ }^{24}$ For this value of e, the domestic firm meets the standard and increases its profits since it obtains exclusive access to the home market (or the concerned segment). Even though the foreign firm suffers a reduction in profits due to the loss of a segment of the market, it has no incentive to meet the standard. This is because it would lose more from a decline in competitiveness in the segment of the market not subject to standards than it would gain from restoring access to the segment subject to standards.

\section{Implications of Alternative Assumptions}

\section{A. Mandatory standards}

So far it has been assumed that if no firm meets the voluntary standard, all

${ }^{24}$ Similarly, the foreign government would have an incentive to introduce standards in the vicinity of 0.63 . 
consumers continue to buy the sub-standard product. In the case of mandatory standards, it would be more appropriate to assume that if no firm meets the standard, then a section of the consumers (those located in the standard-imposing country) buy none of the product.

The changed assumption affects payoffs only for outcome $(N, N)$, i.e. when neither firm meets the standard. So with mandatory standards:

$$
\begin{gathered}
\Pi^{d}(N, N)_{m}=(n-m)(1 / 9 b)\left(a-2 c^{d}+c^{f}\right)^{2} \\
\Pi^{f}(N, N)_{m}=(n-m)(1 / 9 b)\left(a+c^{d}-2 c^{f}\right)^{2}
\end{gathered}
$$

Thus if neither firm has met the standard, firms no longer have access to the entire market but to a shrunken segment. A firm may now be induced to meet a standard even though doing so implies making less profits than in the no standard situation. For instance, if exclusionary standards were mandatory in a sufficiently large section of the market, then the low cost firm would choose to meet them and gain exclusive access to this segment of the market. That is, provided $m$ is sufficiently close to $n$, $\Pi^{f}(N, S)>\Pi^{f}(N, N)_{m}$ when $a-c^{d}<e<a-c^{f}$.

Do the results obtained earlier for voluntary standards hold for the case of mandatory standards? Most of the earlier results are easily generalised since any equilibrium in which at least one firm meets the voluntary standard can also be implemented with mandatory standards. To see this, recall that here voluntary and mandatory standards differ in payoffs only when no firm meets the standard: in the former case, firms still have access to the entire market, while in the latter case, they are deprived of access to a segment of the market. Consider first an equilibrium in which only one firm meets the voluntary standard. If the firm meets the standard when it is voluntary, then it will certainly meet the standard when it is mandatory-since not meeting the standard is less attractive in the latter case. Given that one firm has met the standard, the situation for the other firm is not affected by whether standards are voluntary and mandatory-in either case, if it does not meet the standard, then it must operate in a shrunken market, and if it does, it has access to the entire market. Thus if it chooses not to meet a voluntary standard, it will also not meet a mandatory standard. Similarly, if both firms meet a voluntary standard, they will also meet a mandatory standard. However, it is evident that the converse is not true.

From the policy point of view, mandatory standards are clearly a more powerful tool than voluntary standards. While the efficacy of voluntary standards depends 
on an often indeterminate level of consumer concern, mandatory standards imposed by a government force all consumers in a particular country to behave like concerned consumers. There is correspondingly greater scope for strategically manipulating the situation in favour of domestic firms.

\section{B. Change in Fixed Costs}

Meeting a standard could entail a change in fixed rather than variable costs. The impact of such standards is relatively easy to analyze. If the required expenditure is less than each firm's duopoly profits in the standardised segment, then both firms would meet the standard. If it is greater than either firm's monopoly profits in the standardised segment, then neither firm would meet it. What if a standard were set entailing a fixed expenditure which only one firm would incur? Since the low variable cost firm would make higher absolute monopoly profits in the standardised segment, it would be the firm to meet the standard. The key point here is that the introduction of standards which involve a fixed expenditure cannot discriminate against the relatively efficient firm-unless the high cost firm has certain advantages, for instance, it moves first or has more favourable access to the capital market.

\section{Separability of Costs}

In several situations a firm's decision to meet the standard for a subset of its output need not affect the variable costs of the rest of its output. In this case, a negative cost spillover does not exist and the firm's optimal choice in the standardised segment is independent of what happens in the non-standardised segment. The low cost firm will, therefore, not be inhibited by considerations of loss of relative competitiveness in the non-standardised segment. The result here is similar to that in the case of changes in fixed costs and for similar reasons. The low cost firm will always be better placed than the high cost firm to incur any identical incremental cost to meet a standard.

\section{Other Standard Assumptions}

It is now well known that results in oligopoly theory are sensitive to assumptions regarding the number of competitors, the demand and cost functions, and the form of competition (price or quantity). The Cournot duopoly assumption with linear demand and cost made possible a simple depiction of the strategic interaction between firms that differ in marginal costs. The implications of 
relaxing these assumptions can be briefly discussed.

Even if the number of firms in the market is greater than two, this does not affect the result that the incentive to meet the standard is likely to differ with a firm's marginal cost. If firms compete in quantities but demand is non-linear, or if firms compete in prices, then several possibilities arise. First of all, a generalized cost increase for firms may have profitable consequences by serving to dampen competition between firms. Proposition 3(i) may be affected, because the payoff structure could then be transformed from that of a Prisoners' Dilemma to that of an "assurance game". Each firm would be willing to meet the standard provided others did so. Quantity competition with non-linear demand, and price competition also raise the possibility of strategic complementarity between products of the firms. ${ }^{25}$ A cost increase may then provide strategic benefits to a firm since the resultant less aggressive behaviour (reduced quantity, increased price) would be rewarded by a less aggressive response from its rival. Each firm's incentive to meet the standard would increase, but it is less easy to establish the impact on the relative incentives of the low and high cost firm, especially with price competition when products are differentiated even before standards are introduced.

The impact of relaxing the assumption of constant marginal costs is intuitively obvious. If marginal costs are decreasing in total output, the firms' incentive to meet the standard would be greater. Gaining access to the segment subject to standards would imply a larger output and a reduction in costs, which may even offset the increase in costs required by the standard. In contrast, if marginal costs are increasing in total output, the firm's incentive to meet the standard would be lower. If cost functions of the two firms are similar, then the basic results need not be affected.

\section{Conclusions and Extensions}

The basic result of this paper is that environmental and other standards can be effective strategic variables even when they are strictly non-discriminatory. This has been illustrated using a simple model which has also yielded three more

\footnotetext{
${ }^{25}$ Bulow, et al. (1985) distinguish between strategic substitutes and complements according to whether a more aggressive strategy by one firm (e.g. lower price in price competition, greater quantity in quantity competition, etc.) lowers or raises, respectively, the other firm's marginal profits. With linear demand and quantity competition, as in this paper, products are necessarily strategic substitutes, but with nonlinear demand and quantity competition, or with price competition, products could be strategic complements.
} 
specific results. First, in certain situations, non-discriminatory standards can alter the market outcome in favour of the relatively high-cost firm. Second, a country with a low cost firm would never have an incentive to introduce a standard that the high cost firm cannot meet. Third, if the two firms decide sequentially rather than simultaneously on whether or not to meet a standard, then neither firm may meet a very low standard. Each firm would be deterred from meeting a low standard because the other firm could credibly threaten to do so in retaliation.

The concerns raised by this paper do not apply to all types of standards. In particular, standards which entail a change in fixed rather than variable costs and those which a firm may meet only for a subset of its output (as may be the case for certain product standards), do not favour high cost firms. The greatest concern is raised by standards which entail a change in variable costs and which a firm must meet for its entire output, as is likely to be the case for environmental and labour standards imposed on the production process.

International trade law today insists that all standards be non-discriminatory, and permits voluntary standards on production processes which do not affect product characteristics, but mandatory process standards are allowed only if they affect product characteristics. This paper has shown first, that the central problem is not whether a standard is discriminatory per se but whether it is unilaterally set. Secondly, in so far as voluntary standards also influence consumer behaviour and can lead to market segmentation, their effects may be similar to those of mandatory standards: their domain is the concerned consumer rather than a particular jurisdiction. Third, if unilateral mandatory standards on production processes were allowed, then a powerful strategic tool would be legitimised.

Since the objective here was to highlight the strategic use of standards, the paper has focused on firms' profits rather than social welfare more broadly. In the present context, the social objective for which the standard is introduced, such as environmental conservation, is most relevant. In so far as strategic standards are also likely to have beneficial environmental effects, there is a natural coincidence of interests between environmentalists and domestic industry. Such a coalition of interests may well see the implementation of strategic standards, even though there is a cost to the domestic consumer.

If standards were internationally negotiated rather than unilaterally determined, then countries would be unwilling to accept a profit-reducing standard unless they derived other benefits, such as environmental conservation. In the present context, countries need not oppose the introduction of standards per se, but could 
legitimately challenge the setting of standards at levels which put its firm at a strategic disadvantage. Thus an agreement to have only internationally negotiated standards would ensure that the reason for such standards is the stated policy objective rather than strategic gain.

The model can be extended in at least three directions. First, dynamic considerations can be introduced, in particular when there is growth over time in environmental concern, or in the size of the segment subject to standards. A firm may then choose to meet the standard even when it is not immediately profitable to do so, in order to preempt its rival. Second, while this paper has sought to obtain general results which apply to all marginal cost-increasing standards, it may be useful to model explicitly the specific negative externality which prompts intervention. The socially optimal standard and the strategic standard could then be compared. Finally, one could consider the possibility of the foreign country introducing its own standards. The circumstances in which the threat of retaliatory action by foreign governments would be credible and would influence standards policy could then be analyzed.

\section{Acknowledgements}

The views expressed in the paper are those of the author and should not be attributed to the World Bank. Thanks for useful comments are due to Clemens Boonekamp, Joseph F. Francois, Patrick Low, Bradley McDonald, Abhinay Muthoo, Marcello Olarreaga, Harsha V. Singh, Arvind Subramanian and Scott Vaughan.

Date accepted: 31 May 2000

\section{References}

Barrett, S. (1994), "Strategic Environmental Policy and International Trade," Journal of Public Economics, 54, 325-38.

Bhagwati, J. (1994), "The Demand to Reduce Domestic Diversity among Trading Nations," in J.N. Bhagwati and R.E. Hudec(ed.), Fair Trade and Harmonization: Prerequisites for Free Trade?, MIT Press, Cambridge, Massachusetts and London, England.

Bhagwati, J. and Srinivasan, T.N. (1994), "Does Environmental Diversity Detract from the Case for Free Trade," in J.N. Bhagwati and R.E. Hudec(ed.), Fair Trade and 
Harmonization: Prerequisites for Free Trade?, MIT Press, Cambridge, Massachusetts and London, England.

Brander, J. and Spencer, B. (1984), "Tariff Protection and Imperfect Competition," in Keirzkowski, H. (ed.), Monopolistic Competition in International Trade, Oxford University Press, Oxford.

Bulow, J.I., Geanakoplos J.D. and Klemperer, P.D. (1985), "Multimarket Oligopoly," Journal of Political Economy, 93, 485-511.

Casella, A. (1996), "Free Trade and Evolving Standards," in J.N. Bhagwati and R.E. Hudec, Fair Trade and Harmonization: Prerequisites for Free Trade?, MIT Press, Cambridge, Massachusetts and London, England.

Dixit, A. (1984), "International Trade Policy for Oligopolistic Industries," Economic Journal (suppl.), 94, 1-16.

Eaton, J. and Grossman, G.M. (1986), "Optimal Trade and Industrial Policy under Oligopoly," Quarterly Journal of Economics, 101, 383-406.

Fudenberg, D. and Tirole, J. (1992), Game Theory, MIT Press, Cambridge, Massachusetts.

GATT (1986), The Tokyo Round Agreements, GATT Secretariat, Geneva.

GATT (1994), The Results of the Uruguay Round of Multilateral Trade Negotiations: The Legal Texts, GATT Secretariat, Geneva.

Krattenmaker, T.G. and Salop, S. (1986), Anticompetitive Exclusion: Raising Rivals Costs to Achieve Power over Price, Yale Law Journal, 96, 209-95.

Mattoo, A. and Singh, H.V. (1994), "Eco-Labelling: Policy Considerations," Kyklos, 47, 53-65.

OECD (1991), Environmental Labelling in ACCEDE Countries, Paris.

National Research Council (1995), Standards, Conformity Assessment, and Trade: Into the 21st Century, National Academy Press, Washington, D.C.

Porter, M.E. and van der Linde, C. (1995), "Toward a New Conception of the EnvironmentCompetitiveness Relationship," Journal of Economic Perspectives, 9, 97-118.

Rege, V. (1994), "GATT Law and Environment-Related Issues Affecting the Trade of Developing Countries," Journal of World Trade, 28(3), 95-170.

Robertson, D. (1992), "Trade and the Environment: Harmonization and Technical Standards," in P. Low (ed.), International Trade and the Environment, World Bank Discussion Papers, 59, World Bank, Washington, D.C.

Newbery, D. (1993), "The Impact of EC Environmental Policy on British Coal," Oxford Review of Economic Policy, 9, 66-95.

Roper Organization, Inc. (1990), The Environment: Public Attitudes and Individual Behaviour, a study conducted for S.C. Johnson and Son, Inc.

Salop, S. and Sheffman, D. (1983), "Raising Rivals Costs," American Economic Review, Papers and Proceedings, 73, 267-71.

Seade, J. (1985), "Profitable Cost Increases and the Shifting of Taxation: Equilibrium Response of Markets in Oligopoly," Warwick Economic Research Papers, 260.

Shaked, A. and Sutton, J. (1982), "Relaxing Price Competition through Product Differentiation," Review of Economic Studies, 49, 3-13. 
Simula, M. and Oy, I. (1995), "Trade and Environmental Issues in Forest Production, written for the Inter-American Development Bank, Washington D.C..

Ulph, A. (1992), "The Choice of Environmental Policy Instruments and Strategic International Trade," in Pethig, R. (ed.), Conflicts and Cooperation in Managing Environmental Resources, Springer-Verlag, Berlin.

Ulph, D. (1994), "Strategic Innovation and Strategic Environmental Policy," in Carraro, C. (ed.), Trade, Innovation, Environment, Kluwer Academic Publishers, Dordrecht.

UNCTAD (1995), Environmental Policies, Trade and Competitiveness: Conceptual and Empirical Issues, Report prepared for the Trade and Development Board, TD/B/ WG.6/6, Geneva. 